\title{
Maternal Outcomes of Breastfeeding in King Abdulaziz University Hospital, Saudi Arabia
}

\author{
Lama A. Banjar ${ }^{1}$, MD, Hanan M. Faruqui ${ }^{2}$, MD, Afaf H. Ghunaim³ ${ }^{3}$ MD, \\ Amal F. Almalki ${ }^{4}$, MD, Haifa M. Alshaikh ${ }^{1}$, MD, Mashael Alsamti ${ }^{1},{ }^{M D}$, \\ Hala H. Mosli ${ }^{5}$, MBBS, RCP(C), ABIM, ABEM, Cert Endo, CCD \\ 'Joint Residency Program of Family Medicine, Ministry of Health, Jeddah, Saudi Arabia \\ ${ }^{2}$ Residency Program of Medicine, Dr. Suliman Fakeeh Hospital, Jeddah, Saudi Arabia \\ ${ }^{3}$ Residency Program of Pediatrics, King Abdulaziz Medical City, Jeddah, Saudi Arabia \\ ${ }^{4}$ King Andulaziz University, Jeddah, Saudi Arabia \\ ${ }^{5}$ Department of Medicine, Faculty of Medicine, King Abdulaziz University, Jeddah, Saudi Arabia
}

\section{Correspondence}

Dr. Hala H. Mosli

P.O. Box 80215

Jeddah 21589, Saudi Arabia

e.M: Halamosli100@gmail.com

Submission: 19 April 2017

Accepted: 14 May 2017

\section{Citation}

Banjar LA, Faruqui HM, Ghunaim AH, Almalki AF, Alshaikh HM, Alsamti M, Mosli HH. Maternal outcomes of breastfeeding in King Abdulaziz University Hospital, Saudi Arabia. JKAU Med Sci 2017; 24 (3): 29-38. DOl: 10.4197/Med. 24.3.3

\begin{abstract}
Breastfeeding has a great efficacy on the growing infant, as well as the mother. It has been suggested that breastfeeding promotes postpartum weight loss. Furthermore, it may alter the risk of developing postpartum depression. The aim of this study is to further understand the adherence and the effect of breast milk feeding on developing a postpartum depression and calculating the postpartum weight reduction percentage in comparison to pre-pregnancy weight. A cross-sectional study was conducted in King Abdulaziz University Hospital among 153 mothers, whose infants are less than two years of age. Data were collected by interviewing the mothers using a standard questionnaire designed for the study and the HAMD depression scale with anthropometric measures. $85.62 \%$ of the study sample had breastfed, $43.38 \%$ breastfed for 1 to 2 months, and $24.18 \%$ for 6 months or more. However, the relationship of postpartum depression and breastfeeding was not significant with a P-value $>0.05 .84 .97 \%$ of the included mothers had the same or greater weight than before pregnancy. In conclusion, mothers in King Abdulaziz University Hospital are well adherent to breast milk feeding. The association of breastfeeding to weight loss was not observed as suggested. Mothers with postpartum depression were less adherent to the practice of breastfeeding.
\end{abstract}

\section{Keywords}

Breastfeeding; Depression; Postpartum; Weight loss; Survey

\section{Introduction}

$B$ reastfeeding is a unique biological legacy possibly shared by mothers all over the world ${ }^{[1]}$. It is well established that it is the optimum source of nutrition for the newborn through infancy and recommendations for breastfeeding practice have been issued by a number of professional societies including the American Academy of Pediatrics, the United Nations Children's Fund (UNICEF), World Health Organization 
(WHO) and the American Dietetic Association. Most studies agreed that breastfeeding is beneficial for babies; now a large number of international studies suggest that it also benefits mothers ${ }^{[2]}$. It is proposed that lactation is an efficient way of promoting postpartum weight loss as a result of its high-energy expenditure ${ }^{[3]}$. Some studies reported less than $1 \mathrm{~kg}$ weight changes from pre-pregnancy in mothers who breastfed while other results showed that many factors other than breastfeeding had larger effects on weight retention or postpartum weight loss. While postpartum weight retention is a possible risk factor for obesity and its ensuing medical complications; on the other hand, postpartum depression is a serious health problem, it not only affects the mother's health, it also affects her ability to care for her infant. It has a profound impact on the child's growth parameters ${ }^{[4]}$ by virtue of its impact on maternal interpersonal functioning, disruption of normal infant engagements with the mother and, as a consequence, impaired infant developmental progress ${ }^{[5]}$. The relationship between breastfeeding and the development of postpartum depression has been examined in the literature with the results being quite variable; it is likely that postpartum depression leads to early cessation of breastfeeding, as opposed to breastfeeding altering the risk of depression. In Saudi Arabia, the breastfeeding initiation among mothers ranges from $90-95 \%$ with $83 \%$ complementing their practice with milk formula or fluids $94 \%$ during the first 6 months ${ }^{[6,7]}$, with a trend towards a rapid decline in breastfeeding during the first year of the infant's life ${ }^{[8,9]}$. By conducting this study, we aim to gather more data about breastfeeding in Saudi Arabia to supply WHO with more information about breastfeeding as there is a lack of evidence about breastfeeding indicators in Saudi Arabia that could not be monitored or compared relying on the available data. Furthermore, the maternal outcomes of breast milk feeding have not yet been studied nationally.

The aim of this study is to further understand the adherence and outcomes of breastfeeding on mothers in King Abdulaziz University Hospital (KAUH), Jeddah, Saudi Arabia.

\section{Methods and Materials}

This study is a cross sectional study that aims to assess the frequency of breastfeeding among mothers in Saudi Arabia, the relation between breastfeeding and postpartum depression and the relation between weight loss and breast-feeding.
A sample of one hundred and fifty-three mothers of different ages with different levels of education and whose infants are less than two years of age was taken KAUH. Breastfeeding is defined as mothers who breastfed her healthy or unhealthy child for any given duration as little as 1-2 months up to 6 months and above, exclusively or mixed with formula. Data was collected by interviewing the mothers at the general pediatrics clinic using a standard questionnaire, which includes demographic data (age, nationality, level of education, occupation, number of children, smoking habits), frequency of breastfeeding, duration, difficulties and health education about breastfeeding. Mothers who never breastfed were asked about the cause if it was due to time -wise issue (occupation or workload), opposition to the concept, lack of knowledge, difficulties in the process or presence of barriers (breast/ nipple disease, child with cleft lip / palate, no more milk secreted from the breast and child refusal to breast milk), maternal disease, child medical conditions and emotions. This study evaluates the correlation between postpartum depression and breastfeeding by using Hamilton Rating Scale for Depression (HAMD). The HAMD was developed by Max Hamilton in 1960 as a measure of depressive symptoms that could be used in conjunction with clinical interviews with depressed patients.

Hamilton Rating Scale for Depression form lists 21 items; the scoring is based on the first 17. In the 17-item version, nine of the items are scored on a fivepoint scale, ranging from zero to four. A score of zero represents an absence of the depressive symptom being measured, a score of one indicates doubt concerning the presence of the symptom, a score of two indicates mild symptoms, a score of three indicates moderate symptoms, and a score of four represents the presence of severe symptoms. The remaining eight items are scored on a three-point scale, from zero to two, with zero representing absence of symptom, one indicating doubt that the symptom is present, and two representing clear presence of symptoms. The sum of scores can range from 0 to 54 .

\begin{tabular}{|c|c|}
\hline Score & Degree \\
\hline $0-6$ & Normal \\
\hline $8-13$ & Mild depression \\
\hline $14-18$ & Moderate depression \\
\hline $19-22$ & Severe depression \\
\hline$\geq$ & Very severe depression \\
\hline
\end{tabular}


The relationship between postpartum weight loss and breastfeeding were observed. By measuring current weight in kilograms using weight scalar, and height in meters with calculation of BMI (body mass index = body weight in kilograms divided by height in meter squared) and comparing to self-reported prepregnancy weight.

Breastfeeding and non-breastfeeding mothers were compared to determine which group lost weight more rapidly in the postpartum period.

Statistical analysis was performed using percentage for categorical data and mean (SD) for continuous data was produced by using IBM SPSS Statistics for Windows, Version 20 (IBM Corp., Armonk, NY, USA). Chi-square test-Fisher's exact test was utilized to compare between two proportions with P-value > 0.05 considered significant. Pearson correlation and Spearman correlation were also utilized to measure the direction and strength between variables.

\section{Results}

Our study included 153 mothers with a child between 0 to 2 years of age from $\mathrm{KAUH}$. $83.01 \%$ of them were found to be mothers between ages of 20 to 34 as shown in Table 1.

$90.85 \%$ of the mothers got their first pregnancy between age of 15 to 29 years old (Table 2), and $76.48 \%$ of them got pregnant 1 to 4 times (Table 3).

Table 1. Mothers'age; showing $83.01 \%$ between age of 20 and 34 years old.

\begin{tabular}{|r|c|c|}
\hline Age & Frequency & Percent \\
\hline $15-19$ & 3 & $1.96 \%$ \\
\hline $20-24$ & 35 & $22.87 \%$ \\
\hline $25-29$ & 55 & $35.95 \%$ \\
\hline $30-34$ & 37 & $24.18 \%$ \\
\hline $35-39$ & 14 & $9.15 \%$ \\
\hline $40-44$ & 7 & $4.58 \%$ \\
\hline $45-49$ & 2 & $1.31 \%$ \\
\hline Total & 153 & $100.00 \%$ \\
\hline
\end{tabular}

Table 2. Mothers' age at first pregnancy, $90.85 \%$ got their first pregnancy between age of 15-29.

\begin{tabular}{|c|c|c|}
\hline Age at $1^{\text {st }}$ Pregnancy & Frequency & Percent \\
\hline $10-14$ & 4 & $2.61 \%$ \\
\hline $15-19$ & 43 & $28.10 \%$ \\
\hline $20-24$ & 61 & $39.87 \%$ \\
\hline $25-29$ & 35 & $22.88 \%$ \\
\hline $30-34$ & 8 & $5.23 \%$ \\
\hline $35-39$ & 2 & $1.31 \%$ \\
\hline Total & 153 & $100.00 \%$ \\
\hline
\end{tabular}

Selected samples were from different levels of education, where the highest percentages were for mothers with college or university degree $(41.83 \%)$, followed by mothers with high school or diploma (33.99\%). Only $9.80 \%$ of the study sample were illiterate (Table 4). $68.63 \%$ of the sample were unemployed mothers (Table 5). In addition, mothers were asked about their smoking habits and the results showed that $76.47 \%$ of the study sample were non-smokers either as active or passive (Table 6).

Frequency of breast-feeding among our study sample was high, about $85.62 \%$ of the mothers were breast feeders as shown in Chart 1.

Table 3. Mothers' number of pregnancies.

\begin{tabular}{|c|c|c|}
\hline Number of Pregnancies & Frequency & Percent \\
\hline $1-2$ & 71 & $46.40 \%$ \\
\hline $3-4$ & 46 & $30.07 \%$ \\
\hline $5-6$ & 27 & $17.65 \%$ \\
\hline $7-8$ & 7 & $4.58 \%$ \\
\hline $9-10$ & 1 & $0.65 \%$ \\
\hline $11-12$ & 1 & $0.65 \%$ \\
\hline Total & 153 & $100.00 \%$ \\
\hline
\end{tabular}

Table 4. Mothers' level of education, $41.83 \%$ of the study sample were with university degree.

\begin{tabular}{|l|c|c|}
\hline \multicolumn{1}{|c|}{ Level of Education } & Frequency & Percent \\
\hline Illiterate & 15 & $9.80 \%$ \\
\hline Elementary & 22 & $14.38 \%$ \\
\hline High School/ Diploma & 52 & $33.99 \%$ \\
\hline College or University Degree & 64 & $41.83 \%$ \\
\hline \multicolumn{1}{|c|}{ Total } & 153 & $100.00 \%$ \\
\hline
\end{tabular}

Table 5. $68.63 \%$ of the study sample were unemployed.

\begin{tabular}{|c|c|c|}
\hline Current 0 ccupation & Frequency & Percent \\
\hline Unemployed & 105 & $68.63 \%$ \\
\hline Home-based job & 4 & $2.61 \%$ \\
\hline Doctor & 4 & $2.61 \%$ \\
\hline Other & 40 & $26.14 \%$ \\
\hline Total & 153 & $100.00 \%$ \\
\hline Do You Smoke? & Frequency & Percent \\
\hline Active Smoker & 7 & $4.58 \%$ \\
\hline Passive Smoker & 29 & $18.95 \%$ \\
\hline No & 117 & $76.47 \%$ \\
\hline Total & 153 & $100.00 \%$ \\
\hline
\end{tabular}

Table 6. Smoking mothers with active smoking habit were only $4.58 \%$.

\begin{tabular}{|c|c|c|}
\hline Do You Smoke? & Frequency & Percent \\
\hline Active Smoker & 7 & $4.58 \%$ \\
\hline Passive Smoker & 29 & $18.95 \%$ \\
\hline No & 117 & $76.47 \%$ \\
\hline Total & 153 & $100.00 \%$ \\
\hline
\end{tabular}


Mothers who breast-fed their child in this study had some variation in the duration. $43.38 \%$ of mothers breast-fed their child for 1 to 2 months and $24.18 \%$ breast-fed their child for 6 months or more. This is illustrated in Table 7.

As it is illustrated in Table 8, the main cause for mothers to not breast feed their child was due to difficulties in process/barriers (counted at 28.75\%) such as no more milk secreted or child refusal to breast milk. The second most common cause was medical condition of the child (15.96\%).

$81.70 \%$ of the mothers were considered not depressed, $71.24 \%$ out of the $81.70 \%$ of not depressed mothers were breast feeders. $18.3 \%$ of the mothers were depressed, from those mothers $3.92 \%$ were not breast feeding. Depressed mothers were categorized depending on HAMD scale to mildly depressed, moderately depressed, and severely depressed. $12.42 \%$ of the mothers had mild depression, $11.11 \%$ out of the $12.42 \%$ were breast feeders. Mothers with moderate depression were $3.92 \%$ and $2.61 \%$ out the $3.92 \%$ were also breast feeders. Only $1.96 \%$ of the study sample mothers showed to be severely depressed and $1.31 \%$ out of the $1.96 \%$ were not breast feeders as illustrated in Table 9 and Chart 2.

After applying the statistical correlation test between postpartum depression and breast milk feeding, no significant correlated relation was found $(p>0.05)$ and the correlation coefficient was weak $\left(r_{s}\right.$ $=-0.115, r=-0.128)$. The negative correlated coefficient means the more depression the less breast feeding. As shown in Table 10.

$84.97 \%$ of the mothers were found to have the same or extra weight in comparison to their prepregnancy weight, $60.09 \%$ of them gained from $0 \%$ to $20 \%$ additional weight to their original pre-pregnancy weight. The remaining $15.03 \%$ of the mothers lost from $1 \%$ to $30 \%$ of their pre-pregnancy weight. As illustrated in Table 11 and Chart 3.

Chart-1. Percentage of breast milk feeders.

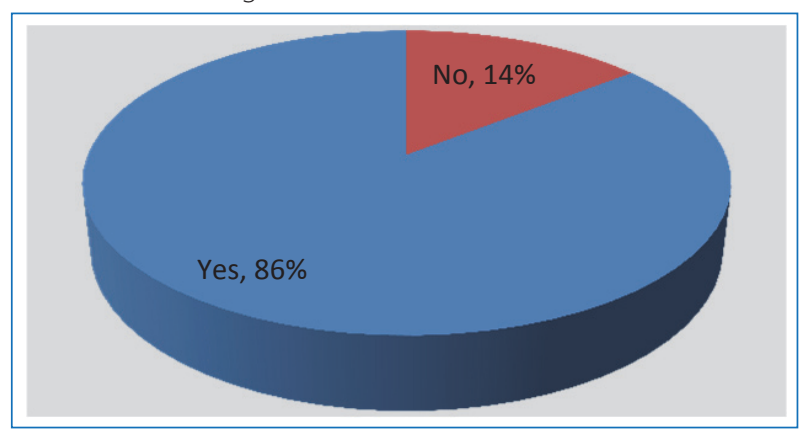

Table 7. Frequency of duration for breastfeeding showing $43.79 \%$ for $1-2$ months.

\begin{tabular}{|l|c|c|}
\hline \multicolumn{1}{|c|}{ Do You Smoke? } & Frequency & Percent \\
\hline No breastfeeding & 22 & $14.38 \%$ \\
\hline 1-2 months & 67 & $43.79 \%$ \\
\hline 2-4 months & 12 & $7.84 \%$ \\
\hline 6 months & 11 & $7.19 \%$ \\
\hline More than 6 months & 26 & $16.99 \%$ \\
\hline Other Total & 15 & $9.81 \%$ \\
\hline \multicolumn{1}{|c|}{ Tor } & 153 & $100.00 \%$ \\
\hline
\end{tabular}

Table 8. Frequency of causes for not breastfeeding ( $n=153)$.

\begin{tabular}{|l|c|c|}
\hline \multicolumn{1}{|c|}{ Cause for Not Breastfeeding the Child } & Frequency & Percent \\
\hline Time-wise issue (occupation or workload) & 5 & $3.27 \%$ \\
\hline Against the concept & 0 & $0.00 \%$ \\
\hline Lack of knowledge & 1 & $0.65 \%$ \\
\hline Medical condition of the child & 24 & $15.69 \%$ \\
\hline Maternal disease & 6 & $3.92 \%$ \\
\hline Difficulties in the process/barriers & 44 & $28.75 \%$ \\
\hline Emotional problem & 0 & $0.00 \%$ \\
\hline
\end{tabular}

Table 9. Cross tabulation between postpartum depression and breast milk feeding.

\begin{tabular}{|c|c|c|c|c|}
\hline \multirow{2}{*}{\multicolumn{2}{|c|}{ HAMD Manual }} & \multicolumn{2}{|c|}{ Child Breastfeeding } & \multirow{3}{*}{$\begin{array}{c}\text { Total } \\
125\end{array}$} \\
\hline & & \multirow{2}{*}{$\begin{array}{l}\text { No } \\
16\end{array}$} & \multirow{2}{*}{$\begin{array}{l}\text { Yes } \\
109\end{array}$} & \\
\hline & Count & & & \\
\hline Not depressed & $\%$ of Total & $10.46 \%$ & $71.24 \%$ & $81.70 \%$ \\
\hline \multirow{2}{*}{ Mild Depression } & Count & 2 & 17 & 19 \\
\hline & $\%$ of Total & $1.31 \%$ & $11.11 \%$ & $12.42 \%$ \\
\hline \multirow{2}{*}{ Moderate Depression } & Count & 2 & 4 & 6 \\
\hline & $\%$ of Total & $1.31 \%$ & $2.61 \%$ & $3.92 \%$ \\
\hline \multirow{2}{*}{ Very Severe Depression } & Count & 2 & 1 & 3 \\
\hline & $\%$ of Total & $1.31 \%$ & $0.65 \%$ & $1.96 \%$ \\
\hline \multirow{2}{*}{ Total } & Count & 22 & 131 & 153 \\
\hline & $\%$ of Total & $14.38 \%$ & $85.62 \%$ & $100.00 \%$ \\
\hline
\end{tabular}


Chart-2. Distribution of postpartum depression and breast milk feeding. (HAMD: Hamilton Rating Scale for Depression).

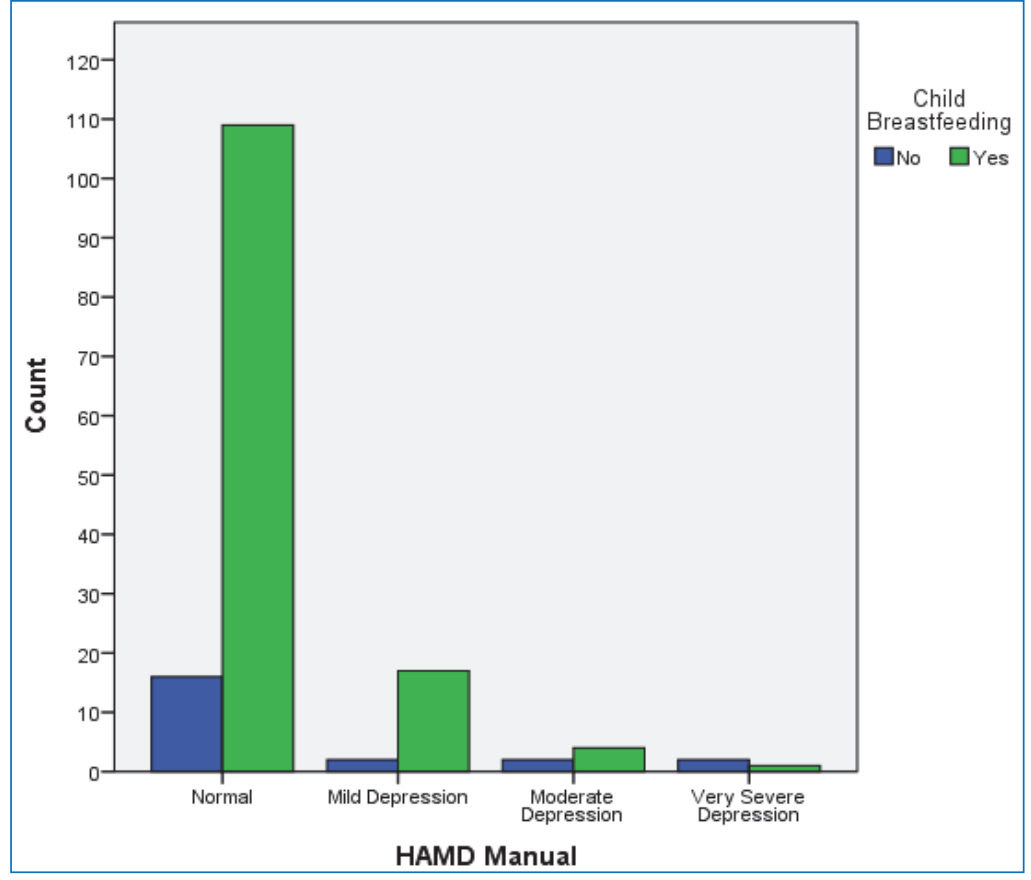

Table 10. Correlation between postpartum depression and breast milk feeding.

\begin{tabular}{|l|l|c|}
\hline \multicolumn{2}{|c|}{ Correlations } & Child Breastfeeding \\
\hline \multirow{3}{*}{ HAMD Manual Scale } & Spearman Correlation & -0.115 \\
\cline { 2 - 3 } & Sig. (2-tailed) & 0.158 \\
\cline { 2 - 3 } & $\mathrm{N}$ & 153 \\
\hline \multirow{2}{*}{$\begin{array}{l}\text { HAMD Depression Scale } \\
\text { Total Score }\end{array}$} & Pearson Correlation & -0.128 \\
\cline { 2 - 3 } & Sig. (2-tailed) & 0.114 \\
\cline { 2 - 3 } & $\mathrm{N}$ & 153 \\
\hline
\end{tabular}

Table 11. Mothers current weight to pre-pregnancy weight ratio.

\begin{tabular}{|c|c|c|}
\hline Cause for Not Breastfeeding the Child & Frequency & Percent \\
\hline $70 \%-79 \%$ & 2 & $1.31 \%$ \\
\hline $80 \%-89 \%$ & 7 & $4.58 \%$ \\
\hline $90 \%-99 \%$ & 14 & $9.15 \%$ \\
\hline $100 \%-109 \%$ & 47 & $30.72 \%$ \\
\hline $110 \%-119 \%$ & 48 & $31.37 \%$ \\
\hline $120 \%-129 \%$ & 21 & $13.73 \%$ \\
\hline $130 \%-139 \%$ & 4 & $2.61 \%$ \\
\hline $140 \%-149 \%$ & 3 & $1.96 \%$ \\
\hline $150 \%-159 \%$ & 3 & $1.96 \%$ \\
\hline $160 \%-169 \%$ & 2 & $1.31 \%$ \\
\hline$>=170 \%$ & 2 & $1.31 \%$ \\
\hline Total & 153 & $100.00 \%$ \\
\hline
\end{tabular}




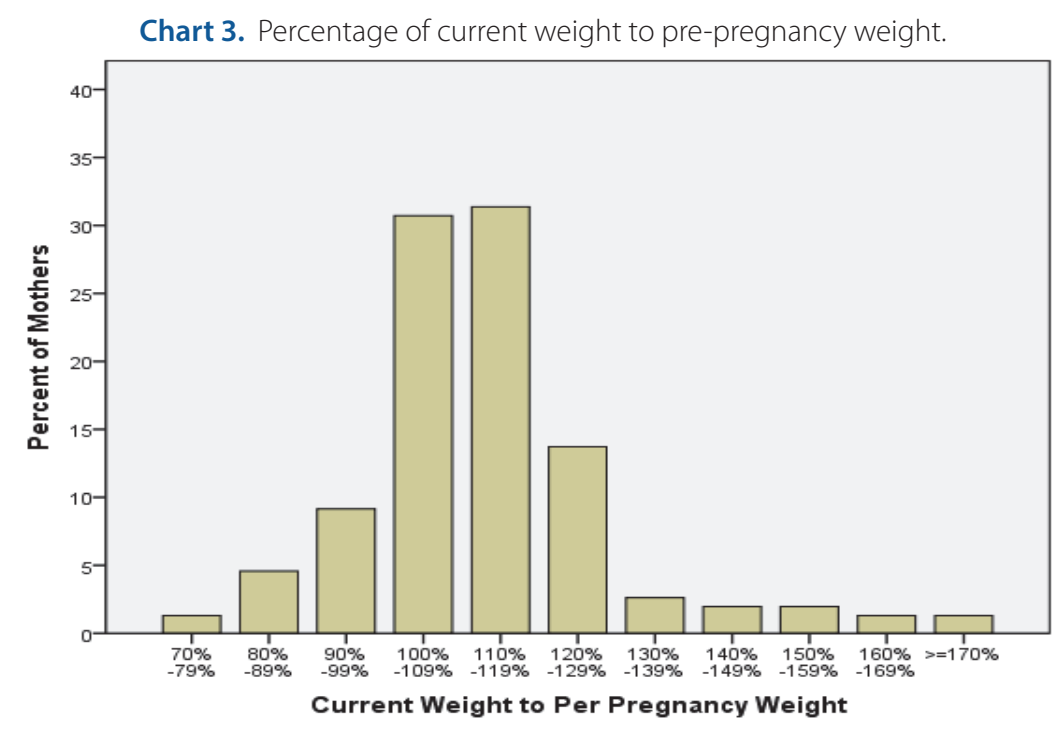

\section{Discussion}

One hundred and fifty-three structured interviews with the mothers were conducted in KAUH on mothers with a mean age of $29 \pm 4$ years old. These mothers had different levels of education, but the majority of them had a university/college degree. Almost two thirds of the participants were unemployed with 1-2 previous pregnancies.

This study revealed a high percentage of breastfeeding among mothers in $\mathrm{KAUH}$, which represented $85.62 \%$ of the total sample. Although these women were breastfeeding, the duration of breastfeeding varied between them; $43 \%$ of mothers breastfed from 1-2 months, $24.18 \%$ of mothers breastfed for 6 months or more. The remainder $14.38 \%$ of mothers, whom did not breastfeed their children at all, claimed that their resistance to the breastfeeding practice was attributed to different causes; these include difficulties in the process of breastfeeding or barriers, such as inadequate breast milk, child refusal, nipple soreness and new pregnancy. The medical condition of the child was the second on the list e.g. the prematurity of the newborn, which leads to longer stays in the hospital that made both the initiation and practice inconvenient.

None of the mothers in the study were against the concept of breastfeeding and only one mother claimed she was ignorant about the importance of the breastfeeding.
We defined breastfeeding as a source of nutrition for the healthy or unhealthy child for any duration, whether it was exclusive or mixed with formula. The results revealed a high prevalence of breastfeeding; and that number per se was possibly due to the open duration of breastfeeding, provided that the majority of mothers in our study adhered to breastfeeding for the first two months only. A conflicting finding is seen in other studies around Saudi Arabia. These may be due to different definitions of breastfeeding (as in duration and exclusivity) and that there are more employed mothers with high education now than ever. Considering the health condition of the child can result in major differences too. Maternal age and the order of the concerned child are also contributing factors ${ }^{[10,11]}$.

Al-Hreashy et al. ${ }^{[12]}$ showed an even higher percentage $\sim 95 \%$ of initiation of breastfeeding, where that study was carried out on mothers who attended a primary care center and a well-baby clinic with almost all healthy babies.

In contrary to a mixed methods study by Eldeek et al. ${ }^{[13]}$ that was conducted in the same hospital as this study-KAUH reported a low level of breastfeeding practice. Their criterion for inclusion in that breastfeeding category was exclusively breastfeeding the child for at least 6 months. The difference between results could be attributed to dividing the type of feeding as exclusive or mixed, and to the selection of mothers with a healthy baby. Furthermore, a 
resembling percentage was observed in a study done by Fida and Al-Aama ${ }^{[14]}$ in KAUH with a breastfeeding period of any duration.

With respect to postpartum depression being proposed as a contributing factor to abandoning breastfeeding, meaning that mothers who suffer from postpartum depression have a less percentage of breastfeeding compared to mothers who don' $t^{[15]}$, our statistical analysis supported this hypothesis, it showed that the more severe the mother's depression was, the less likely it was for her to breastfeed her newborn. A considerable body of research surrounding this subject has proven the same ${ }^{[15-18]}$. By applying the statistical correlation; we found that there is a very weak relation between breastfeeding as a factor that decreases the incidence of postpartum depression. In contrast, a study conducted by Kendal-Tacket ${ }^{[19]}$ and Stewart et al. ${ }^{[21]}$ revealed that breastfeeding has been shown to reduce stress and protect mothers from postpartum depression. Diverse factors could play a role in this; as limiting the duration of breastfeeding could come up with a big change in the results as showed in Hamdan A and Tamim H. ${ }^{[17]}$ Depressive symptomatology in the contrasting studies could be determined by the relationships between postpartum and various strong risk factors that they did not take into consideration ${ }^{[21]}$, as the inability to breastfeed per se is a causative agent of postpartum depression itself ${ }^{[22]}$.

On the other hand, pertaining to pregnancy and postpartum periods being times of increased vulnerability for retention of excess body fat in women, thereare conflicting results in other studies as to whether breastfeeding women lose weight more rapidly than non-breastfeeding women in the postpartum period. Some studies showed no relation between postpartum weight loss and breastfeeding ${ }^{[6,23,24]}$. These inconsistent results have been attributed to differences in the definition of breastfeeding and the timing of baseline measurements. As in Jarlenski et al. ${ }^{[23]}$ breastfeeding was defined as a duration of at least three months of exclusive breastfeeding, while Sámano et al. ${ }^{[24]}$ used a similar definition only to differ in an extra month in the duration. Other studies reported no relationship between postpartum weight loss and breastfeeding ${ }^{[5,6]}$.

Similar to this study, both of Boardley et al..$^{[7]}$ and Greene et al. ${ }^{[8]}$ defined breastfeeding as "any" versus "none". In the current literature, there are other factors that influence postpartum weight change, most importantly gestational weight gain. ${ }^{[9,25]}$ Other factors include pre-pregnancy weight ${ }^{[16,26]}$, race $^{[18,27]}$, parity ${ }^{[26]}$ and age ${ }^{[26]}$. Lastly, living in a high-income society like Saudi Arabia where there is a sedentary life style with minimal dependence on exercise, makes women less concerned about losing the extra weight.

Unlike what we proposed, the results of our statistics showed that there is no direct correlation between postpartum depression and breastfeeding. On the other hand, there is a significant reduction of breastfeeding among mothers who suffer from postpartum depression. Almost $80 \%$ of the mothers in this study were not depressed. Our findings showed that most of the mothers retained their pre-pregnancy weight or even gained extra.

\section{Limitations}

The small sample, which was limited to KAUH patients and lack of standard definitions, were the main limitations of this study. Conducting data exclusively from a hospital can be limited with regards to the study's results. Most of the mothers who were included in the study have a child who suffers from a medical condition, which reflects negatively on the physical and psychological condition of the mother. Excessive stressing about their beloved baby may give rise to postpartum depression among the mothers ${ }^{[21,28]}$. Breastfeeding can be challenging for mothers with a baby admitted in Neonatal Intensive Care Unit ${ }^{[28]}$ or a child who can't tolerate breastfeeding for any reason. Other cofounders like family and father's emotional support were not encountered in this study due to limitation of the type of study. That's why the findings of this study cannot be generalized on the whole population. Another obstacle was a cultural one, which is that most women in Saudi Arabia do not report to their physicians when feeling depressed, or could be simply in denial about their condition. This factor could have influenced the percentages of cases of postpartum depression.

\section{Suggestions for Further Research}

Education of the population and further research are still needed to establish successful breastfeeding and to measure the adherence of breastfeeding among mothers in Saudi Arabia. Studies should be conducted to demonstrate the optimal beneficial duration of breastfeeding for the child's development and health as well as the mother's overall well-being in the postpartum period. An urgent need for more 
robust studies to reliably assess the direct impact of breastfeeding on postpartum weight changes and to explore further the reasons why not all breastfeeding women lose weight.

\section{Conclusion}

This study was held to measure the adherence of mothers in KAUH to breast-feeding practice with its impact on weight loss, and to identify its relation to postpartum depression. The analysis of the data showed a positive attitude of KAUH mothers toward breast-feeding practice where they had high frequency and adherence to it with variable durations. Regarding the impact of breast-feeding on weight loss, it was observed only in $15.03 \%$ of the study sample. Most of the study sample found their weight was unchanged or increased compared to their pre-pregnancy weight after breast-feeding practice for at least 2 months.

On the other hand, postpartum depression showed to have opposed relation with breast-feeding practice, as the data showed mothers who were depressed were less adherent to breast feeding practice according to the severity of their depression (depending on HAMD scale).

\section{Conflict of Interest}

The authors have no conflict of interest.

\section{Disclosure}

None of the authors received any type of commercial support either in forms of compensation or financial for this study. They have no financial interest in any of the products or devices, or drugs mentioned in this article.

\section{Ethical Approval}

Obtained.

\section{References}

[1] Labbock $\mathrm{MH}$. Effects of breastfeeding on the mother. Pediatr Clin North Am 2001; 48(1): 143-158.

[2] Stuebe A. the risks of not breastfeeding for mothers and infants. Rev Obstet Gynecol 2009; 2(4): 222-231.

[3] Hatsu IE, McDougald DM, Anderson AK. Effects of infant feeding on maternal body composition. Int Breastfeed J 2008; 3: 18.

[4] Gross HE, Shaw DS, Moilanen KL, Dishion TJ, Wilson MN. Reciprocal models of child behavior and depressive symptoms in mothers and fathers in a sample of children at risk for early conduct problems. J Fam Psychol 2008; 22(5): 742-751.

[5] Paulson JF, Dauber S, Leiferman JA. Individual and combined effects of postpartum depression in mothers and fathers on parenting behavior. Pediatr 2006; 118(2): 659-668.

[6] Dewey KG, Heinig MJ, Nommsen LA. Maternal weight-loss patterns during prolonged lactation. Am J Clin Nutr 1993; 58(2): 162-166.

[7] Boardley DJ, Sargent RG, Coker AL, Hussey JR, Sharpe PA. The relationship between diet, activity, and other factors, and postpartum weight change by race. Obstet Gynecol 1995; 86(5): 834-838.

[8] Greene GWP, Smiciklas-Wright HP, Scholl TOP, Karp RJM. Postpartum weight change: how much of the weight gained in pregnancy will be lost after delivery? Obstet Gynecol 1988; 71(5): 659-806.

[9] Baker JL, Gamborg M, Heitmann BL, Lissner L, Sørensen TI, Rasmussen KM. Breastfeeding reduces postpartum weight retention. Am J Clin Nutr 2008; 88(6): 1543-1551.

[10] Coulibaly A, Ake Tano O, Bénié Bi Vroh J, Traoré Y, Dagnan NS. [Socioeconomic factors influencing exclusive breastfeeding among primiparous women in Abidjan (Ivory Coast)]. Sante Publique 2014; 26(4): 555-562.

[11] Cunningham J, Jackson K, Oickle D. 2006 Infant Feeding Survey: Factors Influencing Breastfeeding Initiation, Duration and the Introduction of Solids. Leeds, Grenville \& Lanark District Health Unit, 2009.

[12] Al-Hreashy FA, Tamim HM, Al-Baz N, Al-Kharji NH, Al-Amer A, Al-Ajmi H, Eldemerdash AA. Patterns of breastfeeding practice during the first 6 months of life in Saudi Arabia. Saudi Med J 2008; 29(3): 427-431.

[13] Eldeek BS, Tayeb SO, Habiballah SB. Knowledge, attitudes and practice of mothers toward breast feeding at well baby clinic, King Abdulaziz University Hospital. J Am Sci 2012; 8(4): 157-162.

[14] Fida NM, Al-Aama JY. Pattern of infant feeding at a university hospital in Western Canadian J Psychiatry 1997; 42(10): 1061Saudi Arabia. Saudi Med J 2003; 24(7): 725-729.

[15] Dennis CL, McQueen K. Does maternal postpartum depressive symptomatology influence infant feeding outcomes? Acta Paediatr 2007; 96(4): 590-594.

[16] Dennis CL, McQueen K. The relationship between infant-feeding outcomes and postpartum depression: a qualitative systematic review. Pediatrics 2009; 123(4): e736-51.

[17] Hamdan A, Tamim H.The relationship between postpartum depression and breastfeeding. Int J Psychiatry Med 2012; 43(3): 243-259.

[18] Misri S, Sinclair DA, Kuan AJ. Breast-feeding and postpartum depression: is there a relationship? Can J Psychiatry 1997; 42(10): 1061-1065. 
[19] Kendall-Tackett K. A new paradigm for depression in new mothers: the central role of inflammation and how breastfeeding and anti-inflammatory treatments protect maternal mental health. Int Breastfeed J 2007; 2: 6.

[20] Cooper C. Mothers who breastfeed are 50\% less likely to suffer postnatal depression. Accessed: < http://www. independent.co.uk/life-style/health-and-families/healthnews/mothers-who-breastfeed-are-50-less-likely-tosuffer-postnatal-depression-9679416.html>.

[21] Stewart DE, Robertson E, Dennis, C-L, Grace, S.L, \& Wallington, T. Postpartum depression: Literature review of risk factors and interventions. 2003.

[22] Hamdan A, Tamim H, The relationship between postpartum depression and breastfeeding. Int J Psychiatry Med 2012; 43(3): 243-259

[23] Jarlenski MP, Bennett WL, Bleich SN, Barry CL, Stuart EA. Effects of breastfeeding on postpartum weight loss among U.S. women. Prev Med 2014; 69: 146-150.

[24] Sámano R, Martínez-Rojano H, Godínez Martínez E, Sánchez Jiménez B, Villeda Rodríguez GP, Pérez Zamora J, Casanueva E. Effects of breastfeeding on weight loss and recovery of pregestational weight in adolescent and adult mothers. Food Nutr Bull. 2013; 34(2): 123-130.

[25] Lyu LC, Lo CC, Chen HF, Wang CY, Liu DM. A prospective study of dietary intakes and influential factors from pregnancy to postpartum on maternal weight retention in Taipei, Taiwan. Br J Nutr 2009; 102(12): 1828-1837.

[26] Brewer MM, Bates MR, Vannoy LP. Postpartum changes in maternal weight and body fat depots in lactating $v s$. nonlactating women. Am J Clin Nutr 1989; 49(2): 259-265.

[27] Parker JD, Abrams B. Differences in postpartum weight retention between black and white mothers. Obstet Gynecol 1993; 81(5 (Pt 1)): 768-774.

[28] Yurdakul Z, Akman I, Kuşçu MK, Karabekiroglu A, Yaylalı G, Demir F, Ozek E. Maternal psychological problems associated with neonatal intensive care admission. Int J Pediatr 2009; 2009: 591359. 
التثائج الأمهات من الرضاعة العربية السعوديةية في مستشفى جامعة الملك عبد العزيز،

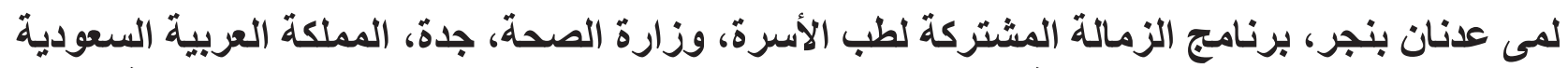

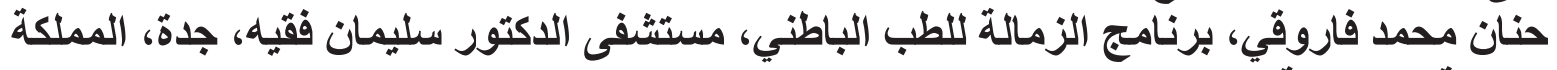
العربية السعودية عفاف حسن غنيم، برنامج الزمالة لطب الأطفال، مدينة الملك عبد العزيز الطبية، جدة، المملكة العربية السعودية أمل فايز المالكي، جامعة الملك عبد العزيز هيفاء محمد الثيخي، برنامج الزمائة المشتركة لطب الأسرة، وزارة الصحة، جدة، المملكة العربية

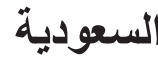
مشاعل مشاعل الصامطي، برنامج الزمالة المشتركة لطب الأسرة، وزارة الصحة، جدة،

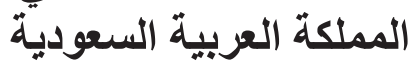
هلا هشام موصلي، قسم الطب الباطني

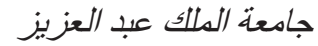
جذة، المبلكة العربية السعودية

الوستخلص. الرضاعة الطبيعية لديها فعالية كبيرة على الرضيع، وكذلك الأم. وقد اقترح أن الرضاعة الراعة الطبيعية تعزز فقدان

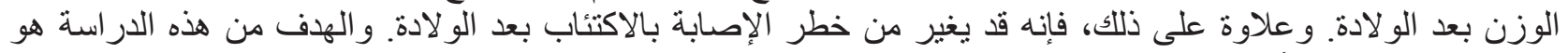

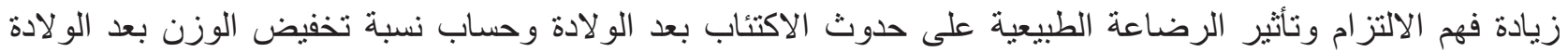

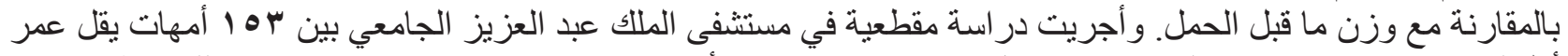

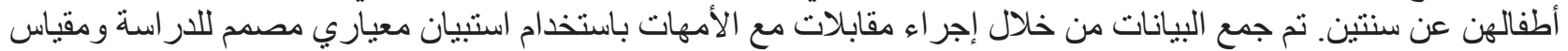

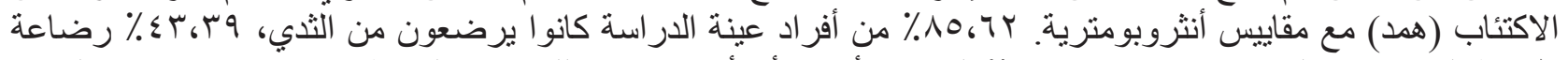

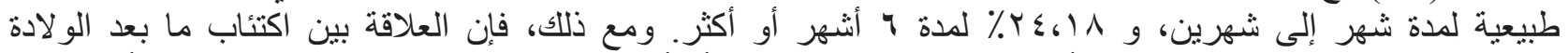

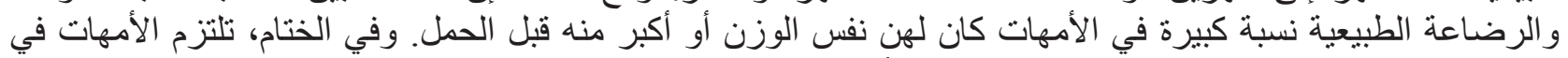

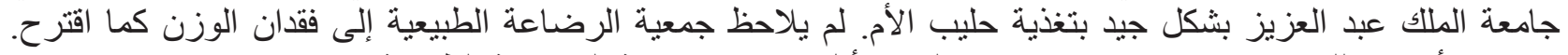
وكانت الأمهات اللو اتي يعانين من اكتئاب ما بعد الو لادة أقل تمسكا بممارسة الرضاعة الرضاعة الطبيعية. 